\title{
A population-based analysis of incentive payments to primary care physicians for the care of patients with complex disease
}

\author{
M. Ruth Lavergne PhD, Michael R. Law PhD, Sandra Peterson MSc, Scott Garrison MD PhD, \\ Jeremiah Hurley PhD, Lucy Cheng MSc, Kimberlyn McGrail PhD
}

See also www.cmaj.ca/lookup/doi/10.1503/cmaj.160692

\begin{abstract}
- Abstract
Background: In 2007, the province of British Columbia implemented incentive payments to primary care physicians for the provision of comprehensive, continuous, guidelineinformed care for patients with 2 or more chronic conditions. We examined the impact of this program on primary care access and continuity, rates of hospital admission and costs.
\end{abstract}

Methods: We analyzed all BC patients who qualified for the incentive based on their diagnostic profile. We tracked primary care contacts and continuity, hospital admissions (total, via the emergency department and for targeted conditions), and cost of physician services, hospital care and pharmaceuticals, for 24 months before and 24 months after the intervention.

Results: Of 155754 eligible patients, $63.7 \%$ had at least 1 incentive payment billed. Incentive payments had no impact on primary care contacts (change in contacts per patient per month: $0.016,95 \%$ confidence interval [Cl] -0.047 to 0.078 ) or continuity of care (mean monthly change: $0.012,95 \% \mathrm{Cl}-0.001$ to 0.024 ) and were associated with increased total rates of hospital admission (change in hospital admissions per 1000 patients per month: $1.46,95 \% \mathrm{Cl} 0.04$ to 2.89 ), relative to preintervention trends. Annual costs per patient did not decline (mean change: $\$ 455.81,95 \% \mathrm{Cl}-\$ 2.44$ to $\$ 914.08$ ).

Interpretation: British Columbia's \$240-million investment in this program improved compensation for physicians doing the important work of caring for complex patients, but did not appear to improve primary care access or continuity, or constrain resource use elsewhere in the health care system. Policymakers should consider other strategies to improve care for this patient population.
$\mathrm{P}$ atients with multiple chronic conditions drive growing demand for health care, ${ }^{1,2}$ but their needs may be poorly met by systems oriented toward acute care and management of single diseases. ${ }^{3}$ Individuals with more than 1 chronic disease comprise $12 \%$ of the Canadian population, but account for almost a quarter of physician consultations and half of hospital days. ${ }^{4}$ Compared with other member countries of the Organisation for Economic Cooperation and Development, Canada performs poorly in accessibility, coordination and quality of care for patients with complex needs. ${ }^{5}$

Several jurisdictions in Canada and internationally have introduced incentive payments for primary care providers targeting the treatment of patients with chronic illnesses. However, despite widespread interest and use, we still do not fully understand the impact of incentive payment programs, especially for patients with complex illness.

The province of British Columbia provides an ideal setting to evaluate the effect of incentive payments for the care of patients with multiple chronic diseases. Other provinces introduced chronic care incentives while making simultaneous changes to payment systems and primary care service delivery models. ${ }^{6,7}$ British Columbia's Complex Care Initiative offers an annual \$315 payment to physicians who accept responsibility for the provision of comprehensive, continuous, guideline-informed care for a patient with 2 or more targeted chronic conditions. ${ }^{8}$ This was implemented in 2007 within the existing fee-for-service payment system, and with no new support for team-based care or other service delivery models. In the year of their implementation, average billings for these
Competing interests: None declared.

This article has been peer reviewed.

Accepted: May 25, 2016 Online: Aug. 15, 2016

Correspondence to: M. Ruth Lavergne, ruth_lavergne@sfu.ca

CMAJ 2016. DOI:10.1503/ cmaj.150858 
incentives exceeded $\$ 9000$ per physician, or more than $3 \%$ of total annual billings. British Columbia's single-payer system allows capture of all relevant use across physician services, hospital care and pharmaceuticals.

More than \$240 million was spent on the Complex Care Initiative between 2007 and 2013. Despite this investment, its impact on primary care delivery, hospital admissions and costs has not been rigorously assessed. Several articles reported favourably on BC's incentivebased primary care reform, ${ }^{8-10}$ claiming it was "improving physician morale and remuneration, improving patient care and revitalizing primary healthcare." ${ }^{\text {S }}$ Some have imputed that it reduces costs of hospital admissions by increasing attachment to physicians (continuity), given the observation that patients with higher continuity cost the system less. ${ }^{8,10,11}$ However, all existing conclusions are based on cross-sectional comparisons of primary care use, hospital admissions, and costs among patients with high and low continuity, or for whom incentives were and were not billed. ${ }^{8,10-13}$ Whereas some patient-level factors were controlled for statistically, no attempts were made to account for unobserved patient- or physician-level factors that might influence both propensity to bill incentives and other aspects of chronic disease care. Therefore, it is highly probable that these results are subject to selection bias.

In our study, we used population-based and provider-specific administrative data and a quasi-experimental design to provide more rigorous estimates of the impact of complex care incentives on primary care access and continuity, rates of hospital admission and total cost of care.

\section{Methods}

\section{Setting}

We studied BC's Complex Care Initiative, which provides a $\$ 315$ annual payment, in addition to regular visit fees, to compensate a primary care physician for the time and skill it takes to care for a patient with 2 or more targeted conditions, and to develop and maintain patient care plans in accordance with BC clinical guidelines. The physician must have provided most primary care physician services for the patient over the preceding year and accepted responsibility for longitudinal, coordinated care of the patient over the ensuing year. Targeted conditions were diabetes, chronic kidney disease, cerebrovascular disease, congestive heart failure, ischemic heart disease, chronic obstructive pulmonary disease and asthma. British Columbia retained the fee-for-service payment system and made no structural changes to primary care provision, such as the introduction of team-based models of practice. In BC, patients have free choice of primary care physicians, and there is no formal rostering (assignment of patients to a responsible physician).

We used linked, de-identified data developed by the BC Ministry of Health and provided through Population Data BC, covering the period from Apr. 1 2005, to Mar. 31, 2012. The Medical Services Plan (MSP) registration file includes a record for all $\mathrm{BC}$ residents who received or were eligible to receive publicly funded health care services, including information about individuals' age, sex, health authority of residence and number of days in each year registered for health insurance in BC. ${ }^{14}$ The MSP payment file includes data on all feefor-service medical services claims paid to physicians. It describes services billed, including the incentive payments, and includes a patient diagnosis code for each encounter. ${ }^{15}$ The Hospital Separations file includes records of all inpatient and surgical day care discharges and deaths for BC residents, including hospital admissions in other provinces. ${ }^{16}$ Each record contains a resource intensity weight variable that can be used to estimate costs. PharmaNet records cost information for all prescriptions dispensed in BC. ${ }^{17}$ All inferences, opinions and conclusions drawn in this article are those of the authors, and do not reflect the opinions or policies of the data stewards.

\section{Patients}

We studied all patients registered with BC's MSP from 24 months before to 24 months after the introduction of the incentive program in April 2007. As is consistent with chronic disease algorithms validated for use in $\mathrm{BC}$ and other Canadian provinces, ${ }^{18,19}$ we identified qualifying patients based on codes from the International Classification of Diseases, 9th Revision [Clinical Modification], and the International Statistical Classification of Diseases and Related Health Problems, 10th revision, associated with 2 outpatient physician visits (excluding laboratory services) or 1 hospital admission during the study period for 2 or more targeted conditions and/or billing of the incentive with a corresponding code developed by the BC Ministry of Health to capture 2 targeted conditions simultaneously (Appendix 1, available at www.cmaj.ca/lookup/suppl/doi :10.1503/cmaj.150858/-/DC1). We excluded individuals who moved into or out of the province during the study period, and who received care from primary care providers not paid 
under the fee-for-service model, because these patients' service use is not completely captured in our data.

\section{Study design}

We used a quasi-experimental interrupted time series design to account for unobservable (but time-invariant) patient and physician characteristics as well as secular trends surrounding the implementation of the incentives. We examined a constant cohort composed of all patients registered throughout the study period or up until death who qualify for the incentive based on their diagnostic profile, regardless of whether an incentive was billed for their care. We calculated population-level means for all outcomes during the study period. We adjusted denominators for all outcomes to include only those patients alive at the start of the month, because we thought that rates and costs per living patient are more interpretable. Before doing so, we verified that death rates were constant throughout the study period, thus ensuring that this adjustment would not affect our findings or conclusions. Our time series analysis estimated any immediate changes in the level or trend of chosen outcomes after the start of the incentive, while simultaneously controlling for pre-existing trends. ${ }^{20}$

\section{Statistical analysis}

We used generalized least squares models and included outcome-specific autoregressive terms to control for correlation over time. We checked linearity of the preintervention trend and included variables to account for seasonality where necessary. Changes in level were assessed using a binary variable that indicated the postincentive period, and changes in trend were assessed with a variable indicating the number of months that had passed since the incentives began. We estimated the absolute change in each outcome as the difference between the counterfactual (the preintervention trend projected forward) and the observed postintervention values, averaged across the 24 months postintervention, with bootstrapped $95 \%$ confidence intervals (CIs). ${ }^{21} \mathrm{We}$ conducted analyses in R 3.0.3 using the nlme and car packages.

We conducted additional analyses to confirm results were consistent using alternate study designs. Devising a methodologically sound control group was complicated for several reasons. We observed that patients without incentives differed in baseline characteristics, with lower continuity, higher rates of hospital admissions and higher costs in the preintervention period, but this can be accounted for by examining preintervention level and trend in analysis with a control group. A greater challenge is that the incentive program both introduced new diagnostic codes that allowed physicians to record 2 conditions per encounter, and provided motivation to document more conditions. This means that patients with qualifying diagnoses identified before and after incentive introduction, and with and without incentives billed, differ in disease severity and patterns of health care use not captured in preintervention data. Finally, contact with the health care system in the period after incentive introduction is both a precondition to receiving the intervention and an outcome of interest. Patients with more frequent contact with the health care system in the postintervention period were more likely to receive the incentive.

With these considerations in mind, we assembled a subcohort of patients with qualifying disease before the study period and examined trends subdivided by whether or not an incentive was billed for their care, as well as in a propensity-matched subset of these patients. We also examined a cohort of only those patients who received incentives, with time zero set as the date of individual incentive billing, not the calendar date of incentive introduction. Finally, we used the fact that the list of eligible conditions was expanded as of Jan. 1, 2010, to confirm findings in a separate cohort of patients with newly qualifying conditions at that time.

\section{Outcome measures}

\section{Primary care access and continuity}

The incentive payment was, in part, intended to ensure that patients with more complex illness would not be "dropped in favour of easier, healthier patients," thereby increasing access to and continuity of primary care among patients in need of complex care. Access was measured as the number of primary care contacts. Continuity was measured as the percent of primary care contacts in a given month with the usual provider of care assigned over the preceding 12 months. The usual provider of care was assigned on a rolling basis, as the physician providing the highest proportion of primary care contacts over a given year.

\section{Hospital admissions}

Although some patients require hospital care even with high-quality primary care, a goal of chronic disease management in primary care is 
to prevent acute events requiring hospital admission, where possible. We examined all acute hospital admissions, admissions through the emergency department and admissions for the targeted chronic conditions. The latter is similar to ambulatory care sensitive conditions, in that there is substantial overlap between the targeted conditions, and those identified as ambulatory care sensitive. ${ }^{22}$
Costs

Better primary and secondary preventive care may reduce need for high-cost services such as acute inpatient care, and therefore overall health care costs. ${ }^{23}$ We tracked total (constant dollar) spending including the following categories: outpatient primary care, outpatient specialty care, laboratory and diagnostic services (excluding magnetic resonance imaging, which

Table 1: Characteristics of the study population

\begin{tabular}{|c|c|c|c|c|}
\hline \multirow[b]{2}{*}{ Characteristic } & \multicolumn{3}{|c|}{ No. (\%) of patients } & \multirow[b]{2}{*}{$\begin{array}{l}\text { Standardized } \\
\text { difference }\end{array}$} \\
\hline & $\begin{array}{c}\text { Total } \\
n=155754\end{array}$ & $\begin{array}{l}\text { Incentive within the study } \\
\text { period } \\
n=99215\end{array}$ & $\begin{array}{l}\text { No incentive within the } \\
\text { study period } \\
n=56539\end{array}$ & \\
\hline \multicolumn{5}{|l|}{ Sex* } \\
\hline Female & $72969(46.8)$ & $46393(46.8)$ & $26576(47.1)$ & 0.01 \\
\hline Male & $82629(53.1)$ & $52738(53.2)$ & $29891(52.9)$ & \\
\hline \multicolumn{5}{|l|}{ Age, yr } \\
\hline$<45$ & $6141(3.9)$ & $2451(2.5)$ & $3690(6.5)$ & 0.13 \\
\hline $45-74$ & $88113(56.6)$ & $57205(57.7)$ & $30908(54.7)$ & \\
\hline$\geq 75$ & $61500(39.5)$ & 39559 (39.9) & $21941(38.8)$ & \\
\hline \multicolumn{5}{|c|}{ No. of chronic conditions (at the end of the study period) } \\
\hline 2 & $19085(12.3)$ & $10274(10.4)$ & $8811(15.6)$ & -0.35 \\
\hline 3 & $58585(37.6)$ & 37634 (37.9) & $20951(37.1)$ & \\
\hline 4 & $41819(26.8)$ & $27899(28.1)$ & $13920(24.6)$ & \\
\hline 5 & $22196(14.3)$ & $14399(14.5)$ & 7797 (13.8) & \\
\hline$\geq 6$ & $14069(9.0)$ & $9009(9.1)$ & $5060(8.9)$ & \\
\hline \multicolumn{5}{|l|}{ Health authority* } \\
\hline Interior & $45471(29.2)$ & $28661(28.9)$ & $16810(28.5)$ & 0.22 \\
\hline Fraser & $61441(39.5)$ & $38128(38.5)$ & $23313(42.0)$ & \\
\hline Vancouver Coastal & $20699(13.3)$ & $13159(13.3)$ & $7540(13.6)$ & \\
\hline Vancouver Island & $19840(12.8)$ & $14918(15.1)$ & $4922(8.7)$ & \\
\hline Northern & $8139(5.2)$ & $4256(4.3)$ & $3883(6.9)$ & \\
\hline \multicolumn{5}{|c|}{ Timing of qualifying disease } \\
\hline Before study & $51460(33.0)$ & $31168(31.4)$ & $20292(35.9)$ & 0.56 \\
\hline Before incentives & $30481(19.6)$ & $12584(12.7)$ & $17897(31.7)$ & \\
\hline After incentives & $73813(47.4)$ & $55463(55.9)$ & $18350(32.5)$ & \\
\hline \multicolumn{5}{|c|}{ No. of incentives billed } \\
\hline 0 & $56559(36.3)$ & - & $56539(100.0)$ & 2.87 \\
\hline 1 & $34004(21.8)$ & $34004(34.3)$ & - & \\
\hline 2 & $37604(24.1)$ & 37604 (37.9) & - & \\
\hline$\geq 3$ & $27587(17.7)$ & $27587(27.8)$ & - & \\
\hline $\begin{array}{l}\text { Died within study } \\
\text { period }\end{array}$ & $23403(15.0)$ & $6222(6.3)$ & $17181(30.4)$ & -0.66 \\
\hline
\end{tabular}


is not captured in our data), all pharmaceutical costs (regardless of payer), inpatient acute care and inpatient elective care. Physician and pharmaceutical costs are based on billing data, and hospital costs are derived using resource intensity weights for each separation, and reported in 2010/11 constant dollars.

This study was approved by the Behavioural Research Ethics Board at the University of British Columbia.

\section{Results}

We identified 155754 eligible patients. Of these, $99215(63.7 \%)$ had a least 1 incentive billed for their care (Table 1). Those with incentives billed within the study period were older, had more chronic conditions and were more likely to live in the Vancouver Island Health Authority. They were also more likely to have received their qualifying diagnosis in the later 2 years of the study period, after the introduction of the incentive program.

\section{Primary care access and continuity}

At the beginning of the study, patients had a mean of 1.10 primary care contacts per month (95\% CI 1.09 to 1.11 ), and $77.6 \%$ (95\% CI
$77.0 \%$ to $78.1 \%$ ) were with the usual provider of care assigned over the preceding 12 months (Table 2, Figure 1). At the time the incentive program was introduced, there was a very small increase in number of primary care contacts, but the overall change of 0.016 contacts per patient per month (95\% CI -0.047 to 0.078 ) was not significant. We observed an attenuation of the decreasing trend in continuity of care after incentives were introduced, but this did not result in continuity returning to the level observed at baseline and after 2 years of incentive payments, and the mean monthly change was not significant $(0.012,95 \%$ CI -0.001 to 0.024) (Table 2, Figure 1).

\section{Hospital admissions}

At the start of the study period, the study population experienced a mean of 28.3 hospital admissions per 1000 patients per month (95\% CI 28.1 to 28.5) (Table 2, Figure 2). Of these admissions, $65 \%$ were via the emergency department and $57 \%$ were for one of the targeted conditions. There is no evidence that the introduction of incentives decreased any type of hospital admission. In fact, the slope of the postintervention trend was slightly higher than the preintervention trend, corresponding to an

Table 2: Segmented regression estimates and associated 95\% confidence intervals for 155754 patients qualifying for incentives during the study period

\begin{tabular}{|c|c|c|c|c|c|c|}
\hline \multirow[b]{2}{*}{ Variable } & \multirow{2}{*}{$\begin{array}{l}\text { Mean no. of } \\
\text { primary care } \\
\text { contacts per } \\
\text { month }\end{array}$} & \multirow[b]{2}{*}{$\begin{array}{l}\text { Proportion of } \\
\text { visits to usual } \\
\text { provider of care }\end{array}$} & \multicolumn{3}{|c|}{ Hospital admissions, monthly rate per 1000 patients } & \multirow{2}{*}{$\begin{array}{c}\text { Mean monthly } \\
\text { cost per } \\
\text { patient, } \\
2010 / 11 \text { (\$Can) }\end{array}$} \\
\hline & & & Total & $\begin{array}{c}\text { Via the } \\
\text { emergency } \\
\text { department }\end{array}$ & $\begin{array}{l}\text { For targeted } \\
\text { conditions }\end{array}$ & \\
\hline $\begin{array}{l}\text { Intercept } 24 \\
\text { months before } \\
\text { incentive } \\
\text { billing* }\end{array}$ & $\begin{array}{c}1.10 \\
(1.09 \text { to } 1.11)\end{array}$ & $\begin{array}{c}0.776 \\
\text { (0.770 to } 0.781)\end{array}$ & $\begin{array}{c}28.3 \\
\text { (28.1 to } 28.5)\end{array}$ & $\begin{array}{c}18.5 \\
\text { (18.1 to } 19.0)\end{array}$ & $\begin{array}{c}16.0 \\
(15.9 \text { to } 16.1)\end{array}$ & $\begin{array}{c}588.20 \\
(581.39 \text { to } \\
595.01)\end{array}$ \\
\hline $\begin{array}{l}\text { Preincentive } \\
\text { trendt }\end{array}$ & $\begin{array}{c}0.0020 \\
(0.0015 \text { to } \\
0.0025)\end{array}$ & $\begin{array}{c}-0.0008 \\
(-0.0012 \text { to } \\
0.0004)\end{array}$ & $\begin{array}{c}0.002 \\
(-0.011 \text { to } \\
0.014)\end{array}$ & $\begin{array}{c}0.023 \\
(-0.006 \text { to } \\
0.052)\end{array}$ & $\begin{array}{c}0.037 \\
(0.029 \text { to } 0.045)\end{array}$ & $\begin{array}{c}2.50 \\
\text { (2.02 to } 2.99)\end{array}$ \\
\hline $\begin{array}{l}\text { Change in level } \\
\text { after incentive } \\
\text { introduction } \neq\end{array}$ & $\begin{array}{c}0.019 \\
(0.009 \text { to } 0.030)\end{array}$ & $\begin{array}{c}-0.0054 \\
(-0.0128 \text { to } \\
0.0019)\end{array}$ & $\begin{array}{c}0.50 \\
(0.23 \text { to } 0.77)\end{array}$ & $\begin{array}{c}0.51 \\
(-0.06 \text { to } 1.08)\end{array}$ & $\begin{array}{c}0.07 \\
(-0.10 \text { to } 0.23)\end{array}$ & $\begin{array}{c}35.81 \\
\text { (25.85 to } 45.78)\end{array}$ \\
\hline $\begin{array}{l}\text { Mean monthly } \\
\text { changeף }\end{array}$ & $\begin{array}{c}0.016 \\
(-0.047 \text { to } \\
0.078)\end{array}$ & $\begin{array}{c}0.012 \\
(-0.001 \text { to } \\
0.024)\end{array}$ & $\begin{array}{c}1.46 \\
\text { (0.04 to } 2.89)\end{array}$ & $\begin{array}{c}1.0 \\
(-0.1 \text { to } 2.2)\end{array}$ & $\begin{array}{c}0.5 \\
(-0.8 \text { to } 1.9)\end{array}$ & $\begin{array}{c}37.98 \\
(-0.20 \text { to } 76.17)\end{array}$ \\
\hline \multicolumn{7}{|c|}{$\begin{array}{l}\text { * Model fit value } 24 \text { months before incentive introduction. } \\
\text { tSlope or rate of change in the outcome over time, before incentive introduction. } \\
\text { fOne-time increase or decrease in the outcome immediately following incentive introduction. } \\
\text { §Change in slope after incentive introduction relative to the preincentive trend. } \\
\text { १The mean monthly change is the total change over the } 24 \text {-month follow-up period (i.e., the area between the line fit to the points before incentive introduction } \\
\text { projected forward and the line fit to points after incentive introduction), divided by } 24 \text { to reflect the monthly mean. }\end{array}$} \\
\hline
\end{tabular}


additional 1.46 total hospital admissions (95\% CI 0.04 to 2.89 ), 1.0 admissions via the emergency department (95\% CI -0.11 to 2.2 ), and 0.53 admissions for targeted conditions (95\% CI -0.82 to 1.9$)$ per 1000 patients per month.

\section{Costs}

At the start of the study period, mean monthly health care spending was $\$ 588.20$ per patient (95\% CI $\$ 581.39$ to $\$ 595.01$ ), with a positive preintervention slope (Table 2, Figure 3). We observed a jump in total spending following the introduction of incentives, which amounted to an additional $\$ 37.98$ per month $(95 \% \mathrm{CI}-0.20$ to 76.17$)$, or about $\$ 455.81$ (95\% CI $-\$ 2.44$ to
\$914.08) per patient per year. This includes the amount spent on incentive payments, as well as small increases in payments to medical and surgical specialists and acute hospital costs. No changes were observed for pharmaceutical or laboratory spending.

\section{Sensitivity of results to study design}

Among patients with qualifying disease identified before the study period, those who received incentives for their care had higher continuity, fewer hospital admissions and lower costs in the preintervention period than those with no incentives (Appendix 2, available at www.cmaj.ca/ lookup/suppl/doi:10.1503/cmaj.150858/-/DC1).

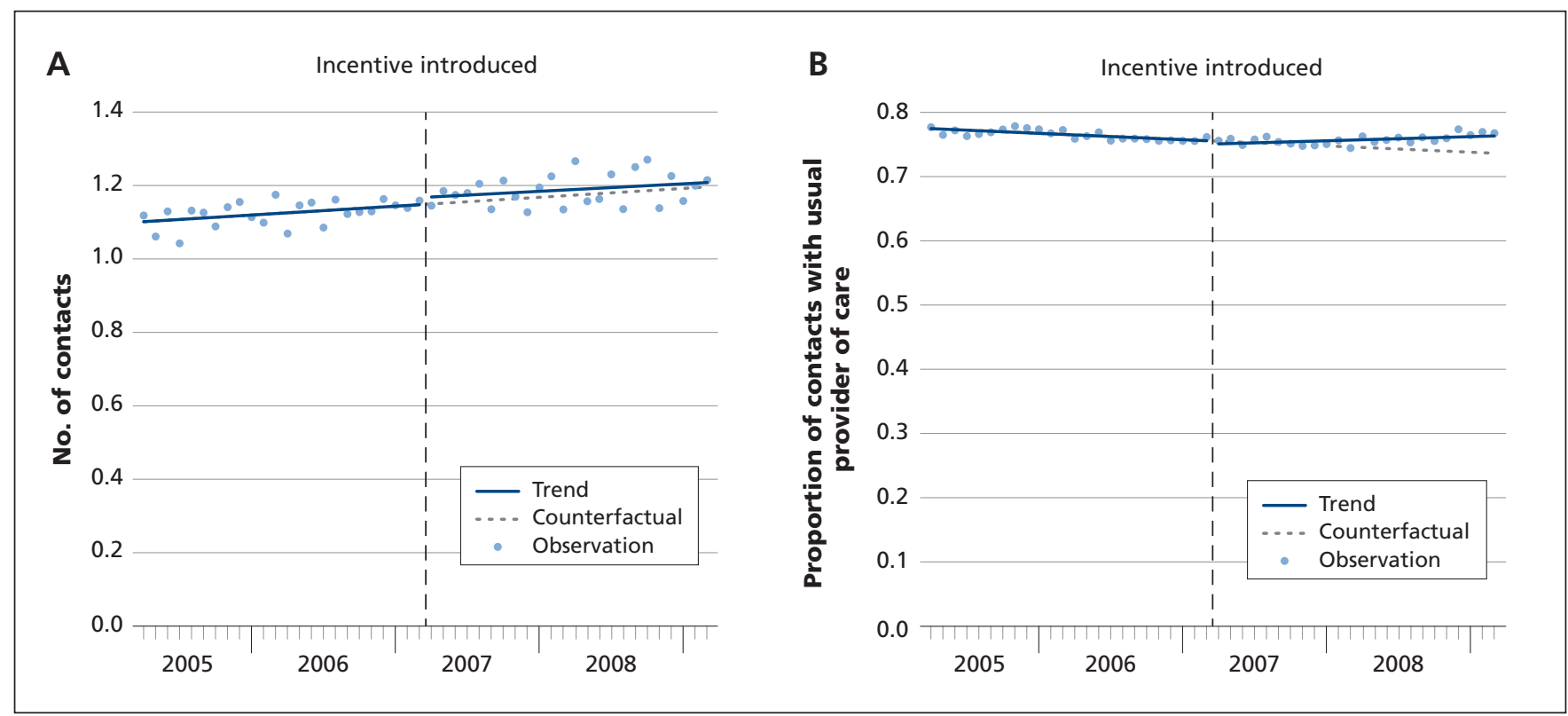

Figure 1: (A) Number of contacts with primary care physicians and (B) mean continuity of care. Note: Continuity of care is defined as proportion of primary care contacts with the usual provider of care (i.e., the physician who provided the highest number of contacts over the preceding year, assigned on a rolling basis).

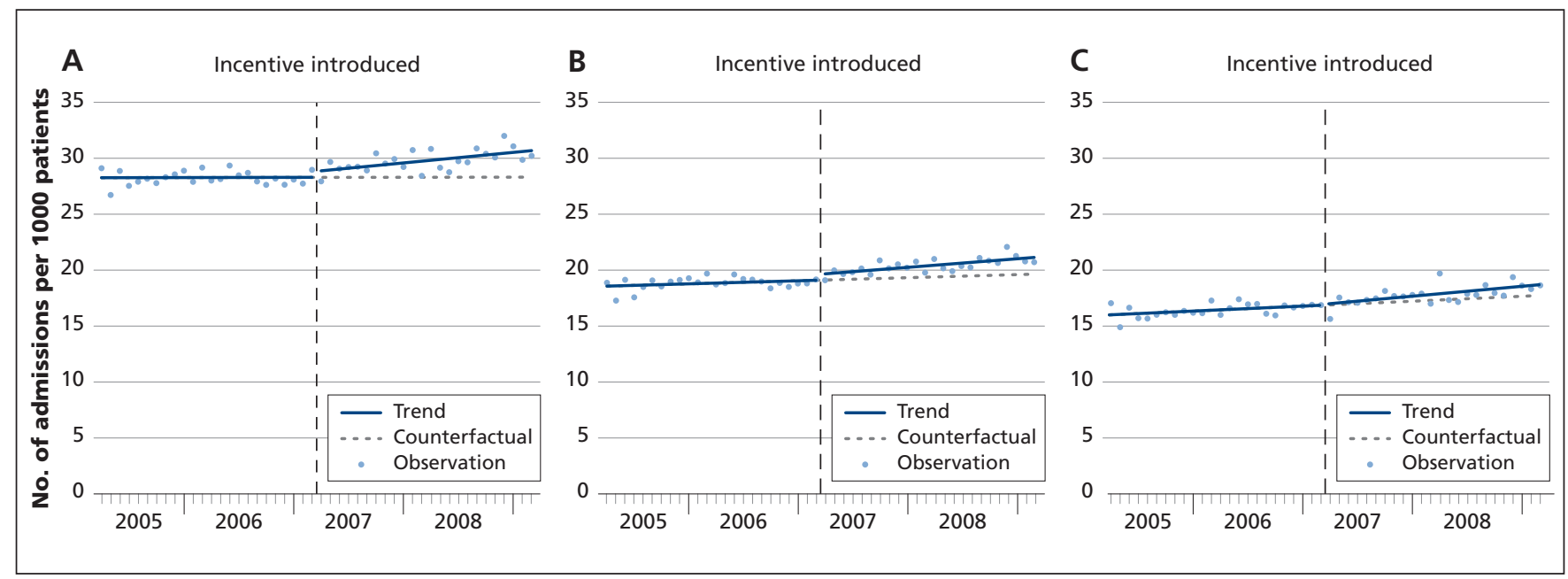

Figure 2: Monthly number of (A) total hospital admissions, (B) hospital admissions via the emergency department and (C) hospital admissions for incentivized conditions (per 1000 patients). 
However, in the postintervention period, patients with incentives had no significant gains in access or decreases in hospital admissions or costs relative to patients without. Findings were consistent in the propensity-matched subset of these patients, except that continuity of care increased modestly (mean monthly change 0.021 , 95\% CI 0.013 to 0.030 ) (Appendix 3, available at www.cmaj.ca/lookup/suppl/doi:10.1503/ cmaj.150858/-/DC1).

Results were also consistent when examining cohorts composed of only patients who received incentives for their care aligned in time on the individual date of incentive billing (Appendix 4, available at www.cmaj.ca/lookup/suppl/ doi:10.1503/cmaj.150858/-/DC1), and when examining patients with conditions newly eligible when the list of conditions was expanded in 2010 (Appendix 5, available at www.cmaj.ca/ lookup/suppl/doi:10.1503/cmaj.150858/-/DC1).

As with the reported findings, after taking into account pre-existing trends, there were no significant improvements in access or continuity, or declines in hospital admissions and costs. The one exception was hospital admissions for targeted conditions, which peaked immediately before incentive billing among patients who received incentives, but declined over the postintervention period, whereas hospital admission for conditions newly targeted by the incentive program in 2010 rose during the postincentive period.

\section{Interpretation}

After accounting for secular trends, we found that BC's complex care incentive payments had no overall impact on the number of primary care contacts or continuity of care, nor did they reduce hospital admissions or total costs. These findings contradict earlier claims of improved continuity and cost savings based on cross-sectional comparisons, ${ }^{8,10-13}$ but are generally consistent with previous research that has found limited impact of incentives within primary care. ${ }^{24}$

The interrupted time series design allowed us to control for physician and patient characteristics that shape both billing of incentives and other aspects of patient care, a weakness of earlier analysis within $\mathrm{BC}^{8,10-13}$ and the likely reason our conclusions differ.

That we observed no reductions in hospital admissions or costs may not be surprising. In studies of the UK Quality and Outcomes Framework, in which incentives were directly tied to measured quality of care, any observed decreases in hospital admissions accompanying observed changes in quality were small, ${ }^{25-27}$ and some studies found no association between measured quality and hospital admissions. ${ }^{28,29}$

Research to date, largely from the United Kingdom and United States, has provided mixed evidence of the effectiveness of these programs..$^{24,30-34}$ Studies of Ontario's pay-forperformance initiatives showed modest improvements in delivery of some preventive services $^{35,36}$ and no change in management of patients with diabetes. ${ }^{37}$ The Ontario picture is complicated by the fact that physician payment mechanisms were also modified, which may have influenced both care for patients with chronic disease ${ }^{38}$ and uptake of incentives. ${ }^{39}$

Most research in this area focuses on care for individual diseases, using the delivery of specific services as indicators of quality. $24,30-34$ Evidence of the effect of incentive-based programs on broader outcomes such as access to primary care, continuity of care,$^{40}$ hospital admissions ${ }^{25-29,41,42}$ and overall resource use $^{30,34,43}$ has been inconclusive.

\section{Limitations}

We cannot rule out that there were other changes in the health care system that coincided with incentive introduction and that influenced measured outcomes. Our observation of similar findings among patients with diseases newly targeted by the incentive program in 2010 offers reassurance that this is unlikely. Results may not fully account for the effect of natural disease progression, leading to observed increases in the trend of hospital admissions in the postintervention period.

Our selection of outcome measures was dictated based on the claims data available, as is

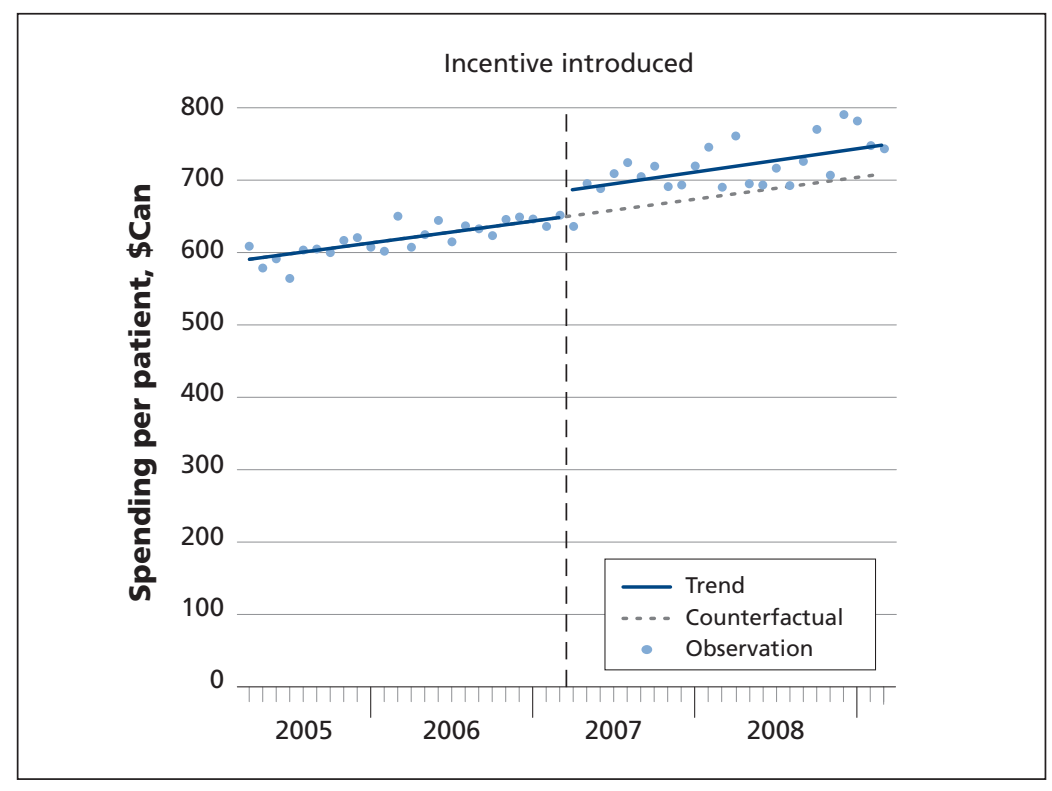

Figure 3: Mean monthly health care spending (2010/11 constant dollars). 
the situation with earlier analysis. ${ }^{8,10-13}$ We may not observe some follow-up contacts under a block payment option discontinued Jan. 1, 2008 , but as there was no increase in contacts in 2008, any effect must be small. We assessed relational continuity of care with a single provider, because the incentives target care provided within a doctor-patient dyad, ${ }^{27}$ but were unable to measure informational or management continuity. ${ }^{23}$ Rates of hospital admission are at best an incomplete proxy for the impact of care on disease progression, but if inaccessible, disorganized or noncontinuous primary care leads to acute admissions, improving primary care would affect hospital admissions soon after policy changes. Our assessment of cost per patient excludes out-of-pocket costs borne by individuals and families other than those for pharmaceuticals, as well as costs of home or long-term care.

\section{Conclusion}

Our analysis shows that incentive payments to individual physicians for the care of patients with 2 or more chronic conditions, in the absence of other changes to primary care payment or delivery, have not changed access or continuity, nor have they prevented hospital admissions or led to cost avoidance elsewhere in the health care system. British Columbia's \$240-million investment in this program may have improved compensation for physicians doing the important work of caring for patients with complex illness, but has not yielded measurable improvements in the outcomes examined. Other strategies are needed to improve care for this patient group.

\section{References}

1. Seniors and the health care system: What is the impact of multiple chronic conditions? Analysis in brief. Ottawa: Canadian Institute for Health Information; 2011.

2. Broemeling A-M, Watson DE, Black C. Chronic conditions and co-morbidity among residents of British Columbia. Vancouver: Centre for Health Services and Policy Research; 2005.

3. Mery G, Wodchis WP, Bierman AS, et al. Caring for people with multiple chronic conditions: a necessary intervention in Ontario. Working paper series volume 2. Toronto: Health System Performance Research Network; 2013.

4. Broemeling AM, Watson DE, Prebtani F. Population patterns of chronic health conditions, co-morbidity and healthcare use in Canada: implications for policy and practice. Healthc $Q 2008$; 11:70-6.

5. Schoen C, Osborn R, Squires DA, et al. New 2011 survey of patients with complex care needs in eleven countries finds that care is often poorly coordinated. Health Aff (Millwood) 2011; 30:2437-48.

6. Hutchison B, Levesque J-F, Strumpf E, et al. Primary health care in Canada: systems in motion. Milbank Q 2011;89:256-88.

7. Glazier RH, Klein-Geltink J, Kopp A, et al. Capitation and enhanced fee-for-service models for primary care reform: a population-based evaluation. CMAJ 2009;180:E72-81.

8. Tregillus VHF, Cavers WJ; General Practice Services Committee. Improving primary care for BC physicians and patients. Healthc Q 2011;14:1-6.

9. Mazowita G, Cavers WJ. Issues in international health policy: reviving full-service family practice in British Columbia. New York: The Commonwealth Fund; 2011.

10. Cavers WJR, Tregillus VHF, Micco A, et al. Transforming family practice in British Columbia: the General Practice Services Committee. Can Fam Physician 2010;56:1318-21.

11. Hollander MJ, Kadlec H, Hamdi R. Increasing value for money in the Canadian healthcare system: new findings on the contribution of primary care services. Healthc $Q$ 2009;12:32-44.

12. Hollander MJ, Tessaro A. Final report: evaluation of chronic disease management payment incentives. Victoria: Hollander Analytical Services; 2011.

13. Hollander MJ, Tessaro A. Final report: complex care incentive payments: fiscal 2009/10. Victoria: Hollander Analytical Services; 2010.

14. British Columbia Ministry of Health. Consolidation file (MSP registration \& premium billing). Victoria: Population Data BC; 2011.

15. British Columbia Ministry of Health. Medical Services Plan (MSP) payment information file. Victoria: Population Data BC; 2011.

16. Canadian Institute for Health Information. Discharge Abstract Database (Hospital separations). Data extract. Population Data BC; 2011.

17. BC Ministry of Health. Data Stewardship Committee PharmaNet. Data extract. BC Ministry of Health; 2011. Available: www.popdata.bc.ca/data (accessed 2016 Aug. 8).

18. Lix L, Yogendran M, Burchill C, et al. Defining and validating chronic diseases: an administrative data approach. Winnipeg: Manitoba Centre for Health Policy; 2006.

19. Chronic Disease Information Working Group. BC chronic disease and selected procedure case definitions. Victoria: BC Ministry of Health; 2015.

20. Wagner AK, Soumerai SB, Zhang F, et al. Segmented regression analysis of interrupted time series studies in medication use research. J Clin Pharm Ther 2002;27:299-309.

21. Zhang F, Wagner AK, Soumerai SB, et al. Methods for estimating confidence intervals in interrupted time series analyses of health interventions. J Clin Epidemiol 2009;62:143-8.

22. Technical note: ambulatory care sensitive conditions (ACSC). Ottawa: Canadian Institute for Health Information. Available: www.cihi.ca/en/technical-note-ambulatory-care -sensitive-conditions-acsc (accessed 2016 Aug. 9).

23. Haggerty JL, Reid RJ, Freeman GK, et al. Continuity of care: a multidisciplinary review. BMJ 2003;327:1219-21.

24. Scott A, Sivey P, Ait Ouakrim D, et al. The effect of financial incentives on the quality of health care provided by primary care physicians. Cochrane Database Syst Rev 2011;(9):CD008451.

25. Harrison MJ, Dusheiko M, Sutton M, et al. Effect of a national primary care pay for performance scheme on emergency hospital admissions for ambulatory care sensitive conditions: controlled longitudinal study. BMJ 2014;349:g6423.

26. Dusheiko M, Gravelle H, Martin S, et al. Does better disease management in primary care reduce hospital costs? Evidence from English primary care. J Health Econ 2011;30:919-32.

27. Dusheiko M, Doran T, Gravelle H, et al. Does higher quality of diabetes management in family practice reduce unplanned hospital admissions? Health Serv Res 2011;46:27-46.

28. Bottle A, Gnani S, Saxena S, et al. Association between quality of primary care and hospitalization for coronary heart disease in England: national cross-sectional study. J Gen Intern Med 2008;23:135-41.

29. Purdy S, Griffin T, Salisbury C, et al. Emergency respiratory admissions: influence of practice, population and hospital factors. J Health Serv Res Policy 2011;16:133-40.

30. Armour BS, Pitts MM, Maclean R, et al. The effect of explicit financial incentives on physician behavior. Arch Intern Med 2001;161:1261-6.

31. Houle SKD, McAlister FA, Jackevicius CA, et al. Does performance-based remuneration for individual health care practitioners affect patient care?: a systematic review. Ann Intern Med 2012;157:889-99.

32. Rosenthal MB, Frank RG. What is the empirical basis for paying for quality in health care? Med Care Res Rev 2006;63:135-57.

33. Christianson JB, Leatherman S, Sutherland K. Lessons from evaluations of purchaser pay-for-performance programs: a review of the evidence. Med Care Res Rev 2008;65(Suppl 6): 5S-35S.

34. Eijkenaar F, Emmert M, Scheppach M, et al. Effects of pay for performance in health care: a systematic review of systematic reviews. Health Policy 2013;110:115-30.

35. Li J, Hurley J, Decicca P, et al. Physician response to pay-forperformance: evidence from a natural experiment. Health Econ 2014;23:962-78.

36. Kiran T, Wilton AS, Moineddin R, et al. Effect of payment incentives on cancer screening in Ontario primary care. Ann Fam Med 2014;12:317-23. 
37. Kiran T, Victor JC, Kopp A, et al. The relationship between financial incentives and quality of diabetes care in Ontario, Canada. Diabetes Care 2012;35:1038-46.

38. Kiran T, Kopp A, Moineddin R, et al. Longitudinal evaluation of physician payment reform and team-based care for chronic disease management and prevention. CMAJ 2015; 17:E494-502.

39. Kantarevic J, Kralj B. Link between pay for performance incentives and physician payment mechanisms: evidence from the diabetes management incentive in Ontario. Health Econ 2013; 22:1417-39.

40. Campbell SM, Reeves D, Kontopantelis E, et al. Effects of pay for performance on the quality of primary care in England. N Engl J Med 2009;361:368-78.

41. Lippi Bruni M, Nobilio L, Ugolini C. Economic incentives in general practice: the impact of pay-for-participation and pay-forcompliance programs on diabetes care. Health Policy 2009; 90:140-8.

42. Fiorentini G, Iezzi E, Lippi Bruni M, et al. Incentives in primary care and their impact on potentially avoidable hospital admissions. Eur J Health Econ 2011;12:297-309.

43. Emmert M, Eijkenaar F, Kemter H, et al. Economic evaluation of pay-for-performance in health care: a systematic review. Eur J Health Econ 2012;13:755-67.

Affiliations: Centre for Health Services and Policy Research, School of Population and Public Health, Faculty of Medicine (Lavergne, Law, Peterson, Cheng, McGrail), University of
British Columbia, Vancouver, BC; Faculty of Health Sciences (Lavergne), Simon Fraser University, Burnaby, BC; Department of Family Medicine (Garrison), University of Alberta, Edmonton, Alta.; Department of Economics (Hurley), McMaster University, Hamilton, Ont.

Contributors: M. Ruth Lavergne, Michael Law, Scott Garrison, Jeremiah Hurley and Kimberlyn McGrail contributed to the study design. Sandra Peterson prepared the analytic data set, and contributed to variable definition and measurement decisions. Lucy Cheng conducted statistical analysis. Kimberlyn McGrail also contributed substantially to data acquisition and the conception of the paper. M. Ruth Lavergne led drafting of the manuscript, and all of the other authors made critical revisions. All authors approved the final version to be published, and agree to act as guarantors of the work.

Funding: This research was funded by the Canadian Institutes of Health Research operating grant "Incentive payments to British Columbia primary care physicians for chronic disease management: What is the effect on patient care?" Michael Law received salary support through a Canadian Institutes of Health Research New Investigator Award, a Canada Research Chair in Access to Medicines and a Michael Smith Foundation for Health Research Scholar Award. 